\author{
Abstracta Iranica \\ Abstracta Iranica Revue bibliographique pour le domaine irano-aryen \\ Volume 34-35-36 | 2017 \\ Comptes rendus des publications de 2011-2013
}

\title{
Philippe Gignoux, Christelle Jullien, Florence Jullien (éds.). Trésors d'Orient. Mélanges offerts à Rika Gyselen
}

Julien Cuny

\section{(2) OpenEdition}

Journals

Édition électronique

URL : http://journals.openedition.org/abstractairanica/42295

DOI : 10.4000/abstractairanica.42295

ISSN : 1961-960X

Éditeur :

CNRS (UMR 7528 Mondes iraniens et indiens), Éditions de l'IFRI

Référence électronique

Julien Cuny, «Philippe Gignoux, Christelle Jullien, Florence Jullien (éds.). Trésors d'Orient. Mélanges offerts à Rika Gyselen », Abstracta Iranica [En ligne], Volume 34-35-36 | 2017, document 33, mis en ligne le 30 juillet 2017, consulté le 26 septembre 2020. URL : http://journals.openedition.org/ abstractairanica/42295 ; DOI : https://doi.org/10.4000/abstractairanica.42295

Ce document a été généré automatiquement le 26 septembre 2020.

Tous droits réservés 


\title{
Philippe Gignoux, Christelle Jullien, Florence Jullien (éds.). Trésors d'Orient. Mélanges offerts à Rika Gyselen
}

\author{
Julien Cuny
}

\section{RÉFÉRENCE}

Philippe Gignoux, Christelle Jullien, Florence Jullien (éds.). Trésors d'Orient. Mélanges offerts à Rika Gyselen. Paris, Association pour les Etudes iraniennes, 2009, 409 p., ill. (Studia Iranica. Cahier 42)

1 On trouvera dans ces Mélanges un ensemble d'articles dont les thèmes touchent de près ou de loin les principaux axes de recherche de la récipiendaire, dans son activité de chercheuse et d'éditrice. La numismatique et la sigillographie, ses deux domaines de prédilection, font l'objet de quatre textes : M. Alram et M.I. Mochiri étudient chacun des émissions sassanides, tandis que 0 . Bopearachchi et M. Blet-Lemarquand proposent deux études sur les premiers monnayages du nord-ouest de l'Inde. J. A. Lerner, A. Saeedi et N. Sims-Williams étudient la sigillographie bactrienne à travers la collection de 17 bulles d'A. Saeedi. L'archéologie sassanide est présente avec un réexamen par P. Callieri des vestiges de Bichapour où l'A. propose d'identifier dans la forteresse qui surplombe la ville le palais de Šābuhr $\mathrm{I}^{\text {er }}$ (cf. Abs. Ir. 32-33, c.r. $\mathrm{n}^{\circ}$ 140). La philologie pehlevie, par l'étude de textes de la pratique conservés sur lin (P. Gignoux) ou sur des ostraca (D. Weber), offre d'intéressantes informations en termes d'histoire économique et sociale.

2 L'histoire sassanide fait l'objet de six articles. N. Garsoïan propose une relecture de la politique sassanide envers leurs sujets arméniens. P. Huyse offre une utile synthèse des données concernant la succession dynastique. K. Mosig-Walburg livre une étude du 
règne du roi Yazdgird $\mathrm{I}^{\mathrm{er}}$ et $\mathrm{J}$. Wiesehöfer une relecture du mouvement et de la révolte mazdakite sous les règnes de Kawād et Husrav $\mathrm{I}^{\mathrm{er}}$. Enfin, F. Jullien publie une très utile première traduction française, accompagnée d'un commentaire par C. Jullien, de la chronique syriaque dite Chronique du Ḥüzistān ou Chronique anonyme de Guidi, qui relate les évènements depuis le règne d'Ohrmizd IV jusqu'à la conquête arabe. Les études du mazdéisme ancien sont représentées par un article de F. Grenet, qui reconnaît dans l'iconographie d'un lit funéraire sogdien de Chine la représentation des rites funéraires zoroastriens, et un article d'A. Panaino qui propose une nouvelle interprétation d'un passage du Yasna (Y. 19,15).

3 La transition entre la période sassanide et l'époque islamique est abordée par une étude du rôle de la grande famille iranienne des Mihrāns dont des membres, convertis à l'islam, ont contribué à en façonner le dogme : la perspective, novatrice, laisse cependant perplexe quant à ses présupposés méthodologiques. F. Thierry offre une analyse très étayée du caractère fondamentalement chinois du langage symbolique déployé (notamment sur les monnaies) par un usurpateur, Shi Siming, probablement d'ascendance paternelle turque plutôt que sogdienne.

4 Trois articles concernent l'époque moderne : F. Richard aborde à travers des documents officiels persans l'histoire des missions catholiques à Ispahan du XVII ${ }^{\mathrm{e}}$ au XIX ${ }^{\mathrm{e}}$ s., M. Tardieu offre une étude de géographie historique des communautés mandéennes à travers le récit du marchand J.-B. Tavernier, et F. Hellot-Bellier s'intéresse aux relations diplomatiques franco-persanes au XIX ${ }^{e}$ siècle. Des traductions de ǵazals de Ḥāfez par G. Lazard agrémentent l'ouvrage.

\section{AUTEURS}

\section{JULIEN CUNY}

Musée du Louvre 